\title{
Despair and Hope: The Healing Power of Listening
}

\author{
Bob Bowen \\ Prag Consulting, Melbourne, Australia \\ Email: bob@matrixofneeds.com
}

How to cite this paper: Bowen, B. (2021) Despair and Hope: The Healing Power of Listening. Health, 13, 591-599.

https://doi.org/10.4236/health.2021.135044

Received: April 6, 2021

Accepted: May 21, 2021

Published: May 24, 2021

Copyright $\odot 2021$ by author(s) and Scientific Research Publishing Inc. This work is licensed under the Creative Commons Attribution-NonCommercial International License (CC BY-NC 4.0). http://creativecommons.org/licenses/by-nc/4.0/

\begin{abstract}
Despair is defined in the dictionary as the complete loss or absence of hope. Many if not most individuals feel a deep sense of despair, made more intense by the loneliness that is part of their lives. The power differentials between those who receive services and those who provide services often intensify this sense of despair and loneliness. It is in that relationship between the powerful and the powerless that loneliness and despair start to build, because there is no bridge between the people who serve and those being served. Those of us who provide services and supports to people in need have been taught to be objective and factual, but facts are only part of the story, the roadway so to speak. The foundations of the bridges between people are found in the emotional connections, the places where the stories of their lives take shape. In order to gain the whole story we must listen to the feelings, where the thematic images behind the words present the story of this person's life.
\end{abstract}

\section{Keywords}

Despair, Hope, Listening, Powerless, Deathmaking, Life-Making

\section{Introduction}

In my work, I often conduct behavioural assessments of individuals whose behaviours pose significant threats of harm to themselves, family members, caregivers, or general community members. My social work training gives me one perspective on this process, as does my training in pastoral counseling and positive behaviour support. However, it is my experience of writing poetry that gives me the broadest set of skills to listen to people, and to listen not just to the words but to the feelings that carry the despair and loneliness that is a large part of the life of many people receiving human services and supports.

In my current role as a behavioral consultant, it is this act of listening with my 
whole being that has empowered me to listen for the themes of the story and the patterns of life and death, hope and despair emanating from the person I am listening to. Over my 40 or so years of experience supporting people in a variety of settings, I have come to understand that the primary themes of life in the margins, where most of the people I support live, are themes of the tension between life and death, and between hope and despair.

Despair is often felt by people receiving human service systems supports and/or interventions [1]. The despair many of the people served in human service settings is made worse by loneliness, as people on the margins of society are often the loneliest in that society [2]. Those of us who enter into relationships as human service professionals with these people for the purposes of support, listen from a position of power over the disempowered [3]. The word "model" as applied to social service settings, regardless of the population served, refers to "consistent pattern in which the behavior of persons is structured by other persons who exercise authority over them." ([4], p. 60) The very word "client" comes from Middle English and Latin, specifically the word cluere, which means to hear or obey, and refers to a person being under the legal protection or patronage of another [5]. There is, in these definitions, a sense of "being under" as opposed a sense of "being with" or, to put it more plainly, being equal.

\section{Case Study}

This tension can be seen in the life of a woman named Isabel for purposes of this article. She had been kidnapped as a teenager by a motorcycle gang in an American state. Isabel was affected by an intellectual disability and was a sexual slave for 5 years. When she was no longer of use to the group, she was abandoned and eventually placed in a group home for people affected by intellectual disabilities.

Isabel told the staff at the home that she had borne a child but could not explain where the child was or what happened to the child. She did not know the gender of the child, and when asked to explain what happened, she said "I was on a bed and a little helicopter was over me. People used a ladder to climb down from the helicopter and took my baby away." In addition to her mild intellectual disability, she was diagnosed as having Delusional Disorder and Schizophrenia NOS. Well-meaning people listened to her story through the lens of her disability, not her humanity.

Prior to my work with her, the behaviour support plan for Isabel was based on her diagnosis of delusional disorder. Because of her intellectual disability she was not considered to be a candidate for therapy and her "ramblings and delusional statements" were ignored. This gave rise to periodic bouts of depression, and she was placed on anti-depressants. She was also sexually abused by her counselor, who groomed her specifically because of the file information stating she often made delusional statements. Her trauma did not stop when she began to receive services and supports, but rather continued until a second individual made an allegation against the counselor, at which point he confessed to abusing Isabel and others. 
In listening to her story, I interpreted her story thematically to provide a second explanation.

Imagine yourself pregnant, on a gurney and being rolled into an operating room. A bright light is above you, and from the light you see hands and fingers moving up and down. You are on medication which makes your vision blurry. You know you are pregnant and that a baby is inside of you. You see the baby lifted up towards the light, never to be seen again. Because of your intellectual disability you have difficulty finding the right words to describe what happened, so you use the words and images from your experiences, including watching television shows.

Listening to the stories of people to gain insight into the themes of their stories requires putting ourselves into their lived experiences as much as possible. This empowers the creation of a hypothesis for what happened to the person you are listening to, and actually using the question- "what happened to you?"-rather than focusing on questions such as "what is wrong with you" [6]. It is in listening to the answers to this question that bridges are built and power is dismantled between those who provide and those who receive human services. Despair and loneliness slowly disappear when listening occurs.

Listening to the second explanation for Isabel's perception of what happened to her provided an alternative understanding for her perception of what happened. By listening to her story and affirming the fear and loss she felt, her behaviour changed and the anger that accompanied her despair dissipated. She was able to grieve the loss of her child, and from her grief she was able to develop hope. Her delusions were alternative interpretations of factual events, a way of understanding what she could not comprehend potentially due to the effects of the anesthetic and her cognitive challenges. After much research her story of giving birth was verified by hospital records, and after months of discussion she made the independent decision not to move forward with attempting to find her child. She was also re-diagnosed, and the diagnoses of Delusional Disorder and Schizophrenia NOS were removed from her file, though they remain in her record.

In order to be able to listen to Isabel and others with similar experiences and challenges, it is critical to, as much as possible, look and listen and empathically recreate her experiences within yourself as the listener.

\section{Discussion}

Isabel is not alone in her loneliness and despair. David Pitonyak writes movingly that Loneliness is the Only Disability [7]. Having gotten your attention with that title, he says, it may be more factual to say that "loneliness is always the primary disability." By addressing the relational needs present in everyone's life, people are generally more able to move forward with their lives because of the presence of hope. Other people can be the source of hope, but not always.

Trauma, events such as abuse and neglect, happen because of the actions and/or inactions of people. The term "deathmaking" was invented to describe 
what happens when people are put on too many psychotropic medications, when they are forced to live with other people they don't know, when they are devalued, living on the margins of society, and whose lives were shortened by the effects of abuse and the overuse of psychoactive drugs [8]. On average, the experience of significant trauma results in a loss of 20 years from average lifespans [9]. Despair can also be brought about in situations where staff respond to and interact in response to behaviour without understanding the communication which is contained within the behaviour [10].

As early as 1936, people were aware of the psychological abuse which comes from the use of power on the part of well-meaning staff who respond to the behavior, not the person using the behavior [11]. Those of us who provide services and supports to others have significant power over those in our care, whatever the setting may be. The trauma which occurs within institutions is increased by the power differential between the servants and those they serve [12].

An example of deathmaking can be seen in an article about a 7-year-old boy whose aide was not present in his classroom to help him deal with the overstimulation he sometimes experiences. As a result, he was banging his head on his desk, and the school resource officer was called. The boy was restrained, handcuffed, and taken to a mental health facility where he stayed for a week [13]. He was treated as an object, not a person and was segregated from his family in the name of treatment. The predictability in his life was provided by a trusted instructional aide who was, unfortunately, not present this day. This is an example of deathmaking at work, demeaning an individual and responding to their behaviour without listening to the themes of loneliness and isolation behind the communication, which is often through behavior (Figure 1).

Life and death, despair and hope are the four points of the quadrant in this model which depicts the struggle of individuals affected by disabilities. For many people "the challenge of life is to learn how to balance hope and despair, to learn how to live with the inevitability of death and suffering" ([14], p. 57).

This graphic can best be explained by the story of Arjun (name changed), a man in his mid-forties in a major city in Canada. When I first met Arjun and his parents, they were in the process of creating a system of supports for their son after he had been in the care of the Ministry of Health and Human Services for 12 years. During this time, Arjun lived in at least 35 different accommodation settings, was psychiatrically hospitalised an average of 3 times per year, with one hospitalisation lasting over six months. He was on multiple psychoactive medications, had no work opportunities, and outside of staff working with him and his parents, had no relationships. The police were called several times a month in his various accommodations due to his aggression.

Today, Arjun has lived in his own home for over 2 years, has worked with a retired carpenter to learn how to build and then sell wooden tables and chairs, and until the COVID-19 pandemic, was actively participating in a number of different community-based activities. He has re-established relationships with 


\section{HOPE}

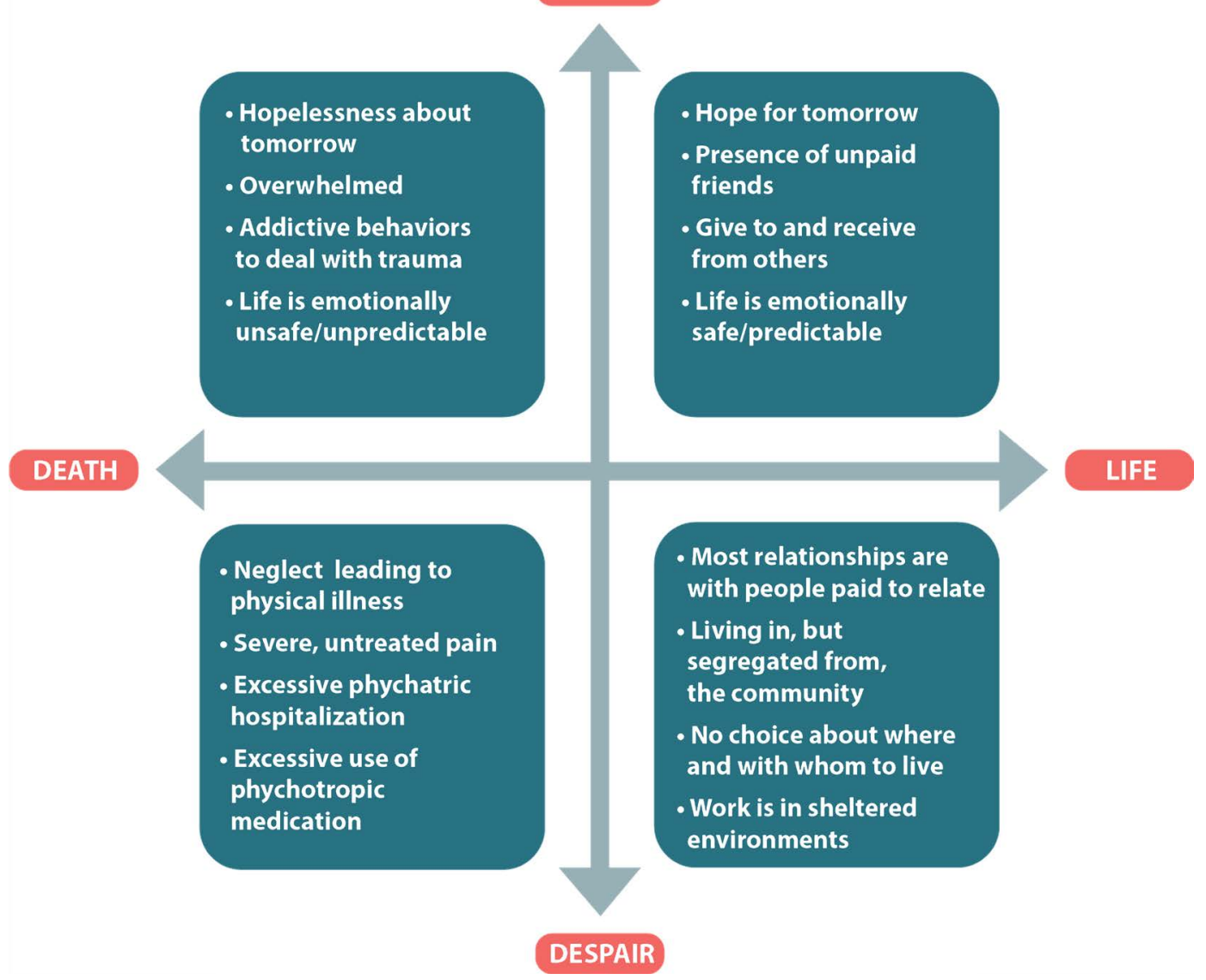

Figure 1. A visual representation of the tension between hope and despair, and life and death.

his siblings and has been reduced from taking 4 different psychoactive medications to 2, with dosage reductions for those medications as well.

Arjun has a diagnosis of schizophrenia, a mild intellectual disability and sleep apnea. However, his symptomology has been significantly reduced, with hallucinatory behaviour occurring less than $10 \%$ of the time compared to over $80 \%$ of the time when I first met him. His attention span for conversations was less than 15 seconds in 2018, and today in 2021 it is measured in hours. Arjun is able to participate in meetings regarding his future and can make fully informed decisions independently.

While he continues to struggle with the complexity of his disabilities, it is a struggle in which he is able to direct the ways in which staff support him. Everyone who interacts with him in a paid relationship is first and foremost a listener. They were taught to listen to the words Arjun used as his hallucinations engaged with him, and the tone of voice, in order to assess how he might be processing the voices he heard, and how to support him to refocus on concrete rather than abstract neurological processing [15]. By listening to his communication and responding to his needs, Arjun's safety has been increased and his hallucinations have been decreased significantly. While Arjun still has periodic episodes of intense pain and struggles with periodic episodes of hallucinations, 
but he has not been psychiatrically hospitalised for over 18 months. There have been no calls to the police for over 18 months.

Arjun has moved from existing to living, from death and despair to life and hope. This was the result of the efforts of multiple professionals from various disciplines guided by the vision Arjun's parents had, and continue to have, that their son can live an ordinary life with meaning and fulfillment. The social relationships Arjun has developed are the most important element in overcoming the effects of trauma [16]. When the only relationships people have are paid, a sense of despair often develops as a result [17]. Despair is a powerful force in the lives of many people in the human service system. Hope, on the other hand, is the antidote to despair [18].

In what many people called the Pandemic Year, 2020 and the first part of 2021 have been marked by a sense of despair springing from hopelessness. Dr. Siu-Hu Wan of the Mayo Clinic in Rochester, MN writes that in a time of hopelessness and despair, the connections between people, the simple acts of kindness and simply being human and simply being present in a time of social distancing is what people need to begin to feel hope [19].

\section{Conclusions}

Allies in Emancipation: Moving From Providing Service to Being of Support is a collection of essays on how people who have focused on providing services can move to "being of support", a term which provides a counterpoint to the service model ingrained in most human service systems [20]. It starts with the attitude of listening to the answers given to the question-what happened to you when...-it is this question, in all its myriad forms, that can move us to an attitude of listening to the communication of the person, both in words and behaviour. It is this attitude of listening that moves us towards the question-how can I be of support? This is a life-making question, by which we can all give up our power and control, hidden within multiple service systems, and move to a position of offering support [21].

The people we support need to be seen for the heroes they are, holding on to hope in the face of despair through the months and years of loneliness as they navigated through our human service system [22]. It is through supporting people, meeting them where they are and listening to the stories of their lives with our hearts and our heads that we can begin to build bridges with the people we support, their families, friends and all the stakeholders in their lives.

\section{Practical Implications and Future Research}

This paper provides a framework for improving listening skills, and also provides people with a model to identify where their organizations or, in the case of individual practitioners, are on the continuum between hope and despair, and life and death. Moving away from coercion is one of the ways human support professionals can develop organizational cultures that support people rather 
than simply addressing their behaviours of concern [23]. By moving away from coercive practices, focusing on being of support rather than providing services and equalizing the power differentials between all the stakeholders in the human supports systems in our countries, we will be able to strengthen the bridges between people and reduce the loneliness, isolation, and pain felt by many in our current systems [24].

Future researchers could integrate the approaches in this paper with Brendan Maher's understanding of delusions as ways of understanding perceptions that cannot be readily understood because they are so far outside the norm of predictable life experiences [25]. For individuals affected by challenges such as Autism Spectrum Disorder (ASD) and/or Intellectual Disabilities (ID), pairing the empathic listening described in this paper with Maher's approach to understanding and making sense of perceptions may be of great value.

\section{Acknowledgements}

During my career in human services and supports, I have been privileged to be invited into relationships with hundreds of different individuals. In the earlier portion of my career I did not know how to build bridges, how to listen, and probably inadvertently wounded some of the people whom I was supposed to support. For that I humbly apologize and beg forgiveness. For the many people who taught me how to listen, who taught me so much about being human, I am deeply grateful.

\section{Human Subjects and Research}

No studies involving human beings or animals were conducted in the writing of this article. Case studies have been anonymized.

\section{Conflicts of Interest}

There are no conflicts of interest experienced by the author. There was no payment by any organization in the writing of this article.

\section{References}

[1] Mental Health Association of Australia (2005) Not for Service: Experiences of Injustice and Despair in Australia's Mental Health System. Mental Health Association of Australia, Melbourne.

[2] Cacioppo, J.T. and Hawkley, L.C. (2009) Loneliness. In: Leary, M.R. and Hoyle, R.H., Eds., Handbook of Individual Differences in Social Behavior, The Guilford Press, New York, 227-240.

[3] Bundy-Fazioli, K., Quijano, L.M. and Bubar, R. (2013) Graduate Students Perceptions of Professional Power in Social Work Practice. Journal of Social Work Education, 49, 108-121. https://doi.org/10.1080/10437797.2013.755092

[4] Wolfensberger, W. (1975) The Origin and Nature of Our Institutional Models (Revised \& Illustrated). Syracuse, NY: Human Policy Press. (Revised and Illustrated Reprint of Chapter Entitled "The Origin and Nature of Our Institutional Models." In R. Kugel, \& W. Wolfensberger (Eds.) (1969) Changing Patterns in Residential 
Services for the Mentally Retarded (pp. 59-171). Washington DC: President's Committee on Mental Retardation.

[5] Bloch, T. (2003) Patient or Client?. BMJ: British Medical Journal, 326, 253.

https://doi.org/10.1136/bmj.326.7383.253

[6] Sweeney, A., Filson, B., Kennedy, A., Collinson, L. and Gillard, S. (2018) A Paradigm Shift: Relationships in Trauma-Informed Mental Health Services. BJPsychAdvances, 24, 319-333. https://doi.org/10.1192/bja.2018.29

[7] Pitonyak, D. (2003) Loneliness Is the Only Real Disability: Implications and Recommendations for Policymakers.

http://dimagine.com/wp-content/uploads/2018/03/NASDDS.pdf

[8] Wolfensberger, W.P. (2002) The New Genocide of Handicapped and Afflicted People. 3rd Rev. Edition, The Author, Syracuse.

[9] Brown, D.W., Anda, R.F., Tiemeier, H., Felitti, V.J., Edwards, V.J., Croft, J.B. and Giles, W.H. (2009) Adverse Childhood Experience and the Risk of Premature Mortality. American Journal of Preventative Medicine, 37, 389-396.

https://doi.org/10.1016/j.amepre.2009.06.021

[10] Durand, V.M. and Moskowitz, L. (2015) Functional Communication Training: Thirty Years of Treating Challenging Behavior. Topics in Early Childhood Special Education, 35, 116-126. https://doi.org/10.1177/0271121415569509

[11] Bryan, W.A. (1936) Administrative Psychiatry. WW Norton and Company, New York.

[12] Unick, G.J., Bassuk, E.L., Richard, M.K. and Paquette, K. (2019) Organizational Trauma-Informed Care: Associations with Individual and Agency Factors. Psychological Services, 16, 134-142. https://doi.org/10.1037/ser0000299

[13] NBCDFW (2017) Child, 7, Allegedly Handcuffed at Dallas Elementary School. http://www.nbcdfw.com/news/local/Child-7-Allegedly-Handcuffed-at-Dallas-Eleme ntary-School-422410273.html

[14] Breitbart, W. (2005) Balancing Life and Death: Hope and Despair. Palliative and Supportive Care, 3, 57-58. https://doi.org/10.1017/S1478951505050108

[15] Binder, J.R., Westbury, C.F., McKiernan, K.A., Possing, E.T. and Medler, D.A. (2005) Distinct Brain Systems for Processing Concrete and Abstract Concepts. Journal of Cognitive Neuroscience, 17, 905-917. https://doi.org/10.1162/0898929054021102

[16] Ludy-Dobson, C.R. and Perry, B.D. (2010) The Role of Healthy Relational Interactions in Buffering the Impact of Childhood Trauma. In: Gill, E., Ed., Working with Children to Heal Interpersonal Trauma: The Power of Play, Guilford Press, New York, 26-43.

[17] Sullivan, L. (2005) Building Alliances after Deleting Disabling Assumptions. In: O'Brien P. and Sullivan, M., Eds., Allies in Emancipation: Moving from Providing Service to Being of Support, Thomson Dunmore Press, South Melbourne, Vic, 163-171.

[18] Hillbrand, M. and Young, J.L. (2008) Instilling Hope into Forensic Treatment: The Antidote to Despair and Desperation. Journal of the American Academy for Psychiatry and Law, 36, 90-94.

[19] O’Brien, P. and Sullivan, M. (2005) Allies in Emancipation: Shifting from Providing Service to Being of Support. Thomson Dunmore Press, South Melbourne.

[20] Hasenfeld, Y. (1987) Power in Social Work Practice. Social Service Review, 61, 469-483. https://doi.org/10.1086/644463 
[21] Wan, S. (2020) Life and Death, Hope and Despair in the Era of Coronavirus Disease 2019. JAMA Cardiology, 5, 985. https://doi.org/10.1001/jamacardio.2020.2420

[22] Duncan, B.L., Miller, S.D. and Sparks, J. (2000) The Heroic Client: A Revolutionary Way to Improve Effectiveness through Client-Directed, Outcome-Informed Therapy. New York, NY: John Wiley \& Sons.

[23] Bowen, B., Privitera, M.R. and Bowie, V. (2011) Reducing Workplace Violence by Creating Healthy Workplace Environments. Journal of Aggression, Conflict and Peace Research, 3, 185-198. https://doi.org/10.1108/17596591111187710

[24] Ones, M. (2000) Hope and Despair at the Front Line: Observations on Integrity and Change in the Human Services. International Social Work, 43, 365-380. https://doi.org/10.1177/002087280004300308

[25] Sakakibara, E. (2019) Intensity of Experience: Maher's Theory of Schizophrenic Delusion Revisited. Neuroethics, 12, 171-182.

https://doi.org/10.1007/s12152-018-9385-4 